(35\%); cardiac (19\%); non-cardiac anomaly (15\%) and syndromal (12\%). Of the 52 infants born alive, 20 (39\%) survived to hospital discharge. Survival with idiopathic hydrops was $28 \%$. Conclusions Overall survival in infants born alive with hydrops was $39 \%$. Idiopathic hydrops was the most common diagnosis and had one of the poorest survival rates.

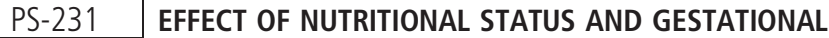 AGE ON THE PHARMACOKINETICS OF RANITIDINE IN NEWBORN CHILDREN}

ILA Lares-Asseff Ismael, BGG Benitez Gaucín Graciela², HJO Juárez-Olguín Hugo ${ }^{3}$, FZT Taruma-Torres Fausto ${ }^{4}$, ATL Toledo-López Alejandra ${ }^{3}$, GPG Pérez-Guillé Gabriela ${ }^{3}$, ACV Camacho-Vieyra Angélica ${ }^{3},{ }^{3}$ AGP Guillé-Pérez Adrián. ${ }^{1}$ Farmacogenómica, Instituto Politécnico Nacional CIIDIR-Unidad Durango México, Durango, Mexico; ${ }^{2}$ Neonatología, Hospital General de Durango México, Durango, Mexico; ${ }^{3}$ Farmacología Clínica, Instituto Nacional de Pediatría México, Ciudad de México, Mexico; ${ }^{4}$ Farmacogenómica, Instituto Politécnico Nacional CIIDIR-Unidad DurangoMéxico, Durango, Mexico

\subsection{6/archdischild-2014-307384.530}

Background and aims The purpose of this study was to develop a population pharmacokinetics model (Pop PK) for ranitidine in newborns, and to determine the effect of nutritional state (NS) and gestational age (GA). The protocol was approved by the bioethics committee.

Methods Fifty newborn (20 females and 30 males) were included. Their (GA) was as follows: 6 pre-term, small (SGA); 20 pre-term, appropriate (AGA); 4 pre-term, large (LGA); 7 SGA of full term; and 13 AGA of full term. Children received 3 $\mathrm{mg} / \mathrm{kg} /$ day IV bolus of ranitidine; two blood samples were collected at each of the following times obtained randomly to: 0 , $0.5,0.75,1,2,4$, and $8 \mathrm{~h}$ from every newborn. The ranitidine levels were determined using HPLC technique. For the population pharmacokinetics (Pop PK) of ranitidine was used with MONOLIX MLXTRANS 4.2.2 ${ }^{\circledR}$ program; data were fitted to bicompartimental model with first-order kinetics.

Results The population values without effect of covariates were obtained clearance $(\mathrm{CL})=0.267 \mathrm{~mL} / \mathrm{min}(\mathrm{CV}=0.685)$; volume of distribution $\left(\mathrm{Vd}_{1}\right)=0.860 \mathrm{~L}(\mathrm{CV}=0.0642) ; \mathrm{Vd}_{2}=0.260 \mathrm{~L}$ $(\mathrm{CV}=0.47$; intercompartmental clearance $(\mathrm{Q})=1.35(0.279$ $\mathrm{mL} / \mathrm{min}$. The covariables that influences clearance of ranitidine are gestational age (term infants from 37 to 42 weeks) with decreased $\mathrm{CL}=0.241 \mathrm{~mL} / \mathrm{min}, \mathrm{p}=0.008$. The $\mathrm{BW}$ increase the $\mathrm{Vd}_{1}=1.03 \mathrm{~L}$ and reduces the value of $\mathrm{Q}=0.556 \mathrm{~mL} / \mathrm{min}(\mathrm{CV}$ $=0.049$ ).

Conclusions Pharmacokinetics of ranitidine depend on (GA) and (NS) of the newborns. This should be considered to determine an adequate dosage treatment, based on respective Pop PK characteristics.

\section{PS-232 DETERMINATION OF RENAL HYPOXIC INJURY IN LBW INFANTS WITH IVH USING NEW BIOMARKERS - KIDNEY INJURY MOLECULE 1 (KIM-1) AND URINARY NEUTROPHIL GELATINASE-ASSOCIATED LIPOCALIN (UNGAL)}

AA Akhundova, SSH Hasanov, NF Panahova, NN Hajieva. Neonatology, Azerbaijan Medical University, Baku, Azerbaijan

10.1136/archdischild-2014-307384.531

Background The brain tissue is very sensitive to hypoxia-ischemia and all the changes occurring within it are well studied and

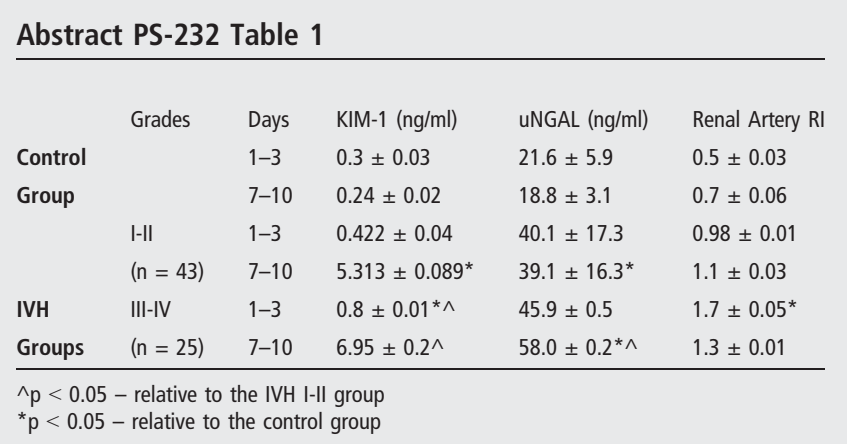

easily diagnosed through laboratory and instrumental methods of examination. In contrast, there are few studies examining the influence of hypoxia-ischemia on kidneys in LBW newborns.

Aim To determine the degree of hypoxic-ischaemic renal injury in LBW infants with various grades of IVH using new biomarkers of renal injury such as KIM-1 and UNGAL.

Methods We studied 68/94 LBW infants (GA 28-36 weeks) with IVH (IVH grades I-II $(\mathrm{N}=43)$ and III-IV $(\mathrm{N}=25)$ ) and conducted neurosonography and Doppler ultrasound tests of renal arteries. Urine samples were collected on days 1-3 and 7-10 after birth to determine KIM-1 and uNGAL levels.

Results The comparison of the IVH groups I-II and III-IV (Table $1)$ and the control group $(\mathrm{N}=26)$ shows that the levels of biomarkers KIM-1 and uNGAL significantly increased in grades III-IV IVH infants $(\mathrm{p}<0,05)$.

Conclusion This study finds that severity of renal damage depends on the grade of IVH and shows that KIM-1 and UNGAL are the most sensitive and early markers of hypoxic damage of tubular parts of a kidney.

\section{PS-233 ACTIGRAPHY IS NOT A RELIABLE METHOD FOR SLEEP STUDIES IN NEONATES}

'J Roué, 'S Rioualen, 'M Dubourg, ${ }^{2} \mathrm{~J}$ Lefranc, ${ }^{3} \mathrm{Z}$ Alavi, ${ }^{3} \mathrm{E}$ Nowak, 'J Sizun. 'Réanimation Néonatale et Pédiatrique, CHRU Brest, Brest, France; ${ }^{2}$ Département de Pédiatrie, CHRU Brest, Brest, France; ${ }^{3}$ Centre d'Investigation Clinique, CHRU Brest, Brest, France

\subsection{6/archdischild-2014-307384.532}

Background and aims Sleep is an essential physiological function in newborn development. Polysomnography is the gold standard for sleep analysis. Extended recordings are difficult with this method. To evaluate actigraphy's reliability to determine sleepwake patterns in newborns in comparison with polysomnography.

Methods Prospective, monocentric study. 48 infants sleep patterns were recorded and assigned into two groups: group 1: 24 preterm neonates at 34-36 weeks gestational age (GA); group 2: 24 term neonates. Polysomnography (PSG) and 2 actigraphs (ACT) Actiwatch Mini ${ }^{\circledR}$ [on arm (arm-ACT), on leg (leg-ACT)] were used during a 3-hour period. Primary endpoint: agreement rate (AR) PSG and leg-ACT with Medium activity threshold setting. Secondary endpoint: AR arm-ACT and leg-ACT. AR's threshold was set at $85 \%$ for validation purposes. Effect of ACT activity threshold setting on a sample of 11 newborns was evaluated.

Results GA, birth weight and age at the recording: 34.5 weeks \pm 0.5 and $39.2 \pm 1.1,2368 \mathrm{~g} \pm 336$ and $3393 \pm 439,6.4$ days \pm 2.8 and $2.54 \pm 0.72$ respectively for group 1 and 2 . Group 1: AR PSG and leg-ACT was 67\% \pm 17 [95\% CI, 60-74] and group 2: $58 \% \pm 17$ [95\% CI, 51-65]. Group 1: AR arm- 